\title{
Proposal, project, practice, pause: Developing a framework for evaluating smart domestic product engagement
}

\author{
Tony Woodall ${ }^{1}$ (D) • Julie Rosborough ${ }^{1} \cdot$ John Harvey ${ }^{1}$
}

Received: 25 February 2016 / Accepted: 2 April 2017 /Published online: 8 May 2017

(C) The Author(s) 2017. This article is an open access publication

\begin{abstract}
Smart homes are fast becoming a reality, with smart TVs, smart meters and other such "smart" devices/systems already representing a substantial household presence. These, which we collectively term "smart domestic products" (SDPs), will need to be promoted, adopted, and normalized into daily routines. Despite this, the marketing canon lacks a substantive discourse on pertinent research. We look to help correct this by melding ideas from organizational sociology, innovation diffusion and appropriation studies, and service dominant logic. Consequently, we suggest a framework for research that responds directly to the specific characteristics of SDPs. Using the SDP eco-system as a context, our framework emphasizes the interplay of embeddedness, practice, value and engagement. It comprises a four-stage horizontal/ longitudinal axis we describe as proposal, project, practice and pause. Cross-sectionally we focus on value, and combine aspects of existing thought to suggest how this impacts each stage of our engagement continuum. We subsequently identify perceived personal advantage as the resultant of these two axes and propose this as the key for understanding consumer and SDP sociomaterial engagement. This article also advances a definition of SDPs and ends with an agenda for further research.
\end{abstract}

Tony Woodall

tony.woodall@ntu.ac.uk

Julie Rosborough

julie.rosborough@ntu.ac.uk

John Harvey

john.harvey@ntu.ac.uk

1 Division of Marketing, Nottingham Business School, Nottingham Trent University, Burton Street, Nottingham NG1 4BU, UK
Keywords Smart homes $\cdot$ Smart domestic products $\cdot$ Service dominant logic $\cdot$ Practice theory $\cdot$ Sociomateriality $\cdot$ Customer engagement $\cdot$ Consumer perceived advantage

\section{Introduction}

We are soon to experience a paradigm shift in the way we live (Moreno-Munoz et al. 2016). This change will neither affect our relationship with friends and family nor directly impact our wealth or ability to live in peace with our neighbors. This change will not determine how we eat, dream, aspire or go about our daily work - unless, that is, we work from home. Initially, at least beyond our front door, we will see no difference at all. However, once we are inside, our "smart" homes will engender a new way of living. They will take care of an array of concerns ranging from energy use, comfort, leisure, healthcare, safety and security (Alam et al. 2012). The smart products incorporated into the smart home will, in turn, integrate with other "smart" contexts - smart grids, smart communities and smart cities. Beyond this they eventually will all interconnect via the Internet of Things (IoT; Ashton 2009).

The IoT blends virtual and physical worlds (Barakat 2016), replacing conventional people-to-people networks with thingto-thing networks. These operate both autonomously from and invisibly to the public (Gubbi et al. 2013). Consumers will seemingly be able to control the technologies introduced or built into their homes, but their connectivity to a larger technological infrastructure means control will only be partial. Once connected to the IoT, they will be subject to a dedicated system of distributed intelligence. The information they provide will potentially be subject to scrutiny, analysis and dissemination. If required, networks can be used to reversecontrol the flow of data, offering information, advice and even instruction back to the homes where they are located (Alam 
et al. 2012). This paradoxically Orwellian Utopia may seem distant, but we have already started the journey. For example, the increasingly ubiquitous smart utility meter, Amazon's Echo, Google's Nest thermostats and even some smart TVs are already linked into networks primed either for private or government intervention (Timm 2016). Contexts in which smart devices reside have consequently been described as context-aware, pervasive computing environments (Chen, Finin and Joshi 2003).

Despite this being an issue of substantial marketing interest, the relevant literature has yet to address smart service diffusion in any substantive way. Wuenderlich, Heinonen, Ostrom, Patricio, Sousa, Voss and Lemmink (2015) make this point too. They also note that it is the "embeddedness" of smart technology that simultaneously represents its most fundamental and challenging characteristic. How, they ask, will this affect consumers' emotional and behavioral responses to "smart" offerings? How will this be factored into decisions on acceptance or rejection? And to what extent will customers of differing socioeconomic and cultural circumstance be willing to normalize embedded services into their daily lives? According to Mani and Chouk (2016), resistance to smart technologies is an ongoing worry for the IoT industry. Issues of security, intrusiveness and uncertain utility are a clear consumer concern. Submitting to external scrutiny and monitoring, even for personal benefit (the "privacy paradox"; Hérault and Belvaux 2014), has been cited as a worry - especially where products were conceived with persuasion in mind. It is perhaps not surprising therefore that uptake of smart domestic products has been slow and abandonment swift (Lazar et al. 2015).

In their review of priorities for service research, Ostrom et al. (2015) highlight the need for more insight into how value emerges in multi-actor, networked, collaborative contexts. They note a need for more understanding of the potential for company, customer and technology integration - and smart contexts represent the frontier for such research. Before pertinent inquiry can begin though, we need to address one central concern: How, given the unique and emergent nature of smart homes and associated products, can marketers begin to understand the factors likely to impact "smart" engagement? Although innovation diffusion research frameworks exist (see later) none answer directly to the specific character of smart technology. This article addresses this deficiency, acknowledging and accommodating factors we believe likely to uncover the effect of "perceived embeddedness" (Wuenderlich et al. 2015). We also respond to Yadav and Pavlou (2014) whose call for the development of domainspecific frameworks in computer-mediated environments sets the principle agenda for our work.

We begin by defining our subject, a category of technological interfaces we call smart domestic products (SDPs). We then draw attention to a range of theories and concepts that inform our perspective on technology and customer engagement. Subsequently, we go on to develop a theoretical framework for SDP engagement focused on two primary axes. For the horizontal we describe a four-phase engagement continuum termed 'proposal, project, practice, pause'. For the vertical we focus on value, and this underpins discussion of an associated property (customer perceived advantage) that we propose as the fundamental unit for future/associated research.

\section{Defining smart domestic products (SDPs)}

An understanding of the context and potential for SDP use is only slowly emerging. Amazon's Echo and Belkin's Crock Pot slow cooker, for example, are part of this domain and represent a category that is growing. These products are designed purely to extend the potential for material consumption, but much of the smart domestic technology currently in use or in development is intended for positive (Botella, Riva, Gaggioli, Wiederhold, Alcaniz and Baños 2012) or transformative (Mick 2006) use. This focuses on the enhancement of either human or ecological states, with personal well-being its aim. Such devices may monitor energy use, parameters of health (e.g., blood pressure, cardiovascular function) or agility - tracking movement via strategically located RFID (radiofrequency identification) sensors. This captures the notion of "ambient assisted living" (Garcia and Rodrigues 2015), the purpose of which is either to support, assist or impose behavioral regimes. All smart technologies are designed to remove the need for conscious reflection - at one extreme helping sustain the user's existing habits (calm technology; e.g., Weiser and Brown 1997) or, at the other, directing the user towards a particular set of actions (persuasive, or captalogical, technology; e.g., Fogg 1999).

We define SDPs - which may be single devices or systems - as technological interfaces that provide or support any type of home service and are embedded into domestic routines. Embeddedness, identified by Moody and White (2003) as structural cohesion, addresses the links between relationships and context (Laud, Karpen, Mulye and Rahman 2015). For a smart context we suggest "embeddedness" implies physical integration into the home; social and psychological integration into the consumers' life; and informational integration into a computer-mediated network of distributed intelligence. Such networks comprise multiple interconnected actors and institutions with diverse aims and objectives. Interfaces may be functionally designed for utilitarian purposes (e.g., smart refrigerators), for hedonic purposes (e.g., Amazon Echo) or as an adjunct to social or personal well-being (e.g., smart meters). The response mechanisms that capture and exploit data provided to and received from SDPs may be primed for calm, informational or captalogical intent. But crucially, all have persuasive potential, and although many recently introduced 
consumer products are largely benign, suppliers will likely be seeking to expand their active capacity. And this, in turn, will impact category perceptions as a whole, perhaps both recalling and reconfiguring Packard's (1957) notion of the "hidden persuader." Figure 1 draws on our discussion and uses both generic and branded examples to illustrate the current SDP domain.

\section{SDPs and engagement}

For both present and future customers to become effective SDP consumers, optimizing benefits for themselves and for other stakeholders (society, governments, sponsors, suppliers), both inertia and anxiety need to be addressed. Customers will need to engage with the technologies at their disposal and achieve symbiosis with the infrastructures that underpin them. Engagement has recently emerged as an issue of substantial interest in the marketing literature, initiated primarily through a special issue of The Journal of Service Research (e.g., Brodie, Hollebeek, Jurić and Ilić 2011). This is not per se a new concept, but its emerged topicality aligns it with other preexisting concepts (e.g., value, experience, customer networks, co-creation) recently rehabilitated in response to the growing influence of Service-Dominant Logic (SDL; see Lusch and Vargo 2014 for a review).

It is suggested that customer engagement (or individual customer/supplier commitment; Sashi 2012) has cognitive, affective and behavioral components (e.g., Brodie et al. 2011; Vivek, Beatty and Morgan 2012). And, as with many other marketing concepts it is graduated in intensity. So et al. (2012), for example, suggest consumers pass through stages of increasing commitment (identification, enthusiasm, attention, absorption and interaction) before achieving full engagement with an offering. SDPs are stereotypical engagement platforms (Ramaswamy 2008). These are interfaces that offer mutually beneficial co-creational opportunities for a wide range of service system stakeholders (Jaakkola and Alexander 2014). However, unless complicit at all levels of engagement SDP consumers will not realize full benefits, while objectives for commercial or social ambition will be considerably undermined. In a smart context therefore, we associate engagement with psychological embeddedness.
Fig. 1 A taxonomy of smart domestic products (SDPs)

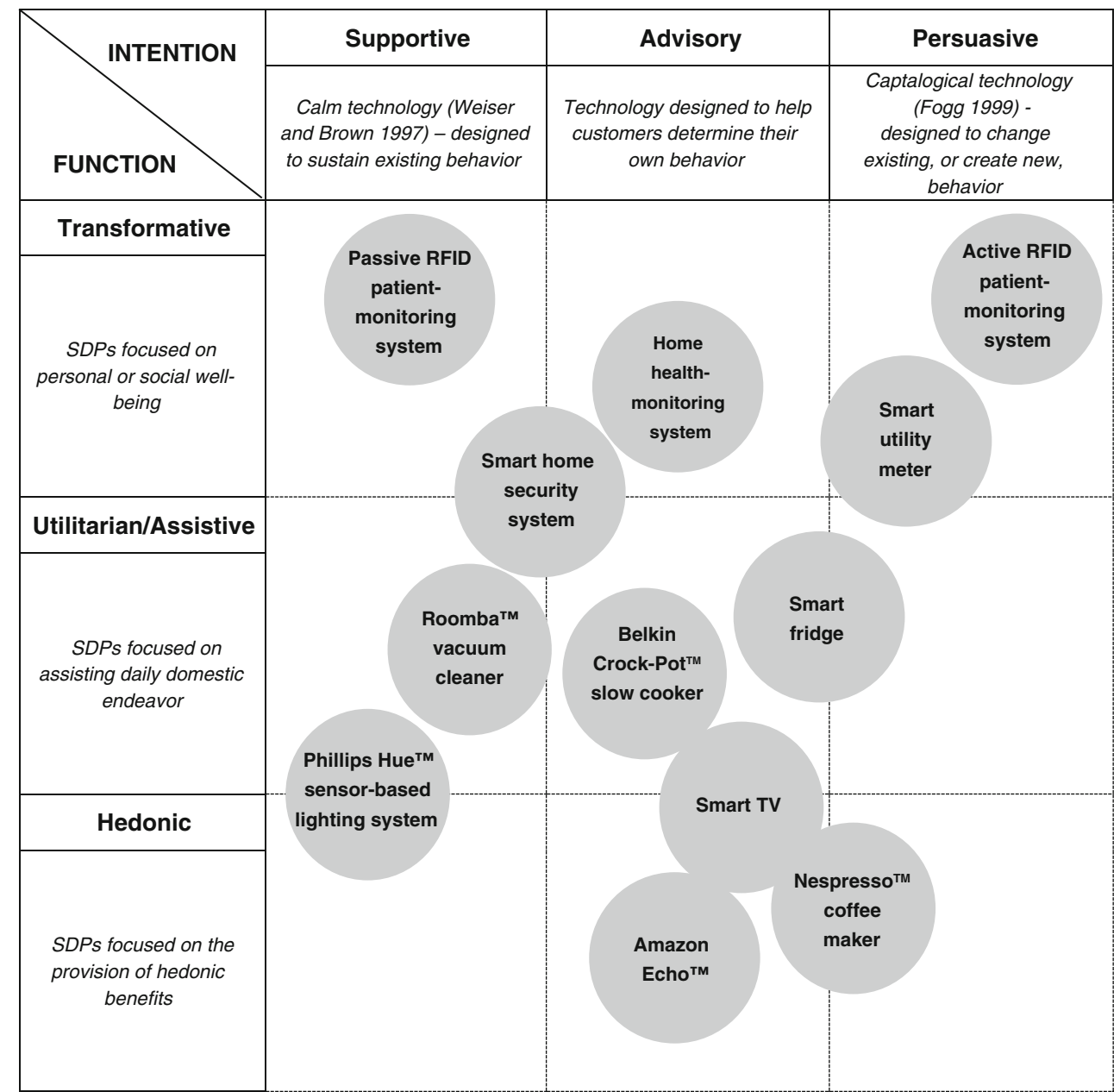


To address all customer types, it is unlikely that a conventional information-deficit approach will work (Owens and Driffill 2008). Endorsing extrinsically defined benefits without prior consumer insight is unlikely to correct any observed engagement discrepancy. Gangale, Mengolini and Onyeji (2013) suggest that key issues for successful smart product engagement are the development of consumer trust and confidence. Secondly, differential targeting is key. These factors are familiar to marketers but, with a few notable exceptions (e.g., Ahn, Kang and Hustvedt 2016; Gray and Bean 2011; Walker 2016), the marketing literature has thus far failed to address the SDP challenge. Rather, it is in engineering, technical sciences, healthcare and applied energy where research has been applied thus far (Wilson, Hargreaves and HauxwellBaldwin 2015).

\section{Engaging with technology}

\section{Marketing and technology}

Overcoming barriers to early levels of engagement - identification, enthusiasm and adoption - is essential to achieving deeper levels of association (absorption and interaction: So et al. 2014). This is especially relevant for people-technology relationships, and in this more general context marketers have not been slow to respond (e.g., Mick and Fournier 1998; Parasuraman 2000; Meuter, Ostrom, Bitner and Roundtree 2003; Ha and Stoel 2009). Marketing interest in the innovation diffusion/engagement field has focused more recently on self-service technologies (SSTs), addressing a range of computer-mediated objects including kiosks of varying types, the internet, interactive voice-response systems, and mobile services (Lin and Hsieh 2011; Wang, Harris and Patterson 2013). SDPs can readily be consigned to the broader category of SST - defined by Meuter, Ostrom, Roundtree and Bitner (2000) as technological interfaces enabling customers to (co)produce services without direct service employee involvement. Critically though, SDPs represent a special, relationally advanced case.

The marketing literature tends to envisage SSTs in largely independent rather than codependent terms, encountered merely as agents or representatives of the service economy. Customers are free to move away and reengage at will from the interfaces concerned; a similar condition to that which applies to other non-domestic products with smart characteristics (e.g., Fitbit/Jawbone; Nike Plus/Adidas miCoach apps). This is perhaps why the SST diffusion-engagement canon (e.g., Hilton and Hughes 2013; Reinders, Frambach and Kleijnen 2015; Åkesson, Edvardsson and Tronvoll 2014) has tended to consider these as operand resources (things that are acted upon) rather than operant resources - entities that have causal efficacy, agency and can consequently be considered integrators of resource (Foundational Premise 9/ Axiom 4, Vargo and Lusch 2016). SDPs are, however, woven into the fabric of daily life, intended to improve the living (Wilson et al. 2015) rather than just the service experience. As a consequence, humans and smart technology might best be considered ontologically similar rather than distinct.

The Service-Dominant Logic (SDL) canon has been slow to spotlight the role of technology and its potential as an integrator of resource (see Campbell, O'Driscoll and Saren 2014; Kleinaltenkamp et al. 2012; and Storbacka, Brodie, Böhmann, Maglio and Nenonen 2016). The progenitors of SDL though have latterly acknowledged technology's importance to value-creation processes. Both Akaka and Vargo (2013) and Löbler and Lusch (2014), for example, suggest technology has both operand and operant characteristics and is therefore an integrator of economic and social resource. However, associated work has focused on business-tobusiness innovation, and the juxtaposition of technology and everyday life is addressed more directly in other disciplines. In the next section we explore this more diverse theoretical base, before moving on to develop a framework for SDP engagement research.

\section{Technology-human relationships}

Drawing on the concept of sociomateriality (Leonardi 2013; Orlikowski 2007) Campbell et al. (2014) argue that "material stuff" is not subservient to human will nor lacking in agency. They concur with Orlikowski (2009) who suggests that those considered to occupy separate human, synthetic and material worlds are effectively "entangled." They should therefore be considered jointly rather than apart. In a "smart" domestic context especially, this suggests embedded technologies should be considered less facilitator and more collaborator. Similarly, although adopting a much wider take on how the animate and inanimate co-habit, Actor Network theorists (e.g., Callon 1986; Latour 1987; Law 1992) posit that once humans and objects interact, they exist differently. In other words, they occur as hybrids rather than as a human/material duality (Latour 1993). This condition results from the "imbrication" (Leonardi 2011) or interweaving of human, material and institutional agency to create a symbiotic other. The components of such a hybrid can simultaneously be dependent, independent and interdependent. Hybridization, we suggest, therefore represents the final condition for SDP physical embeddedness.

Latour (2005) acknowledges that "things" are not conscious or sensible and won't normally instigate activity; yet they can authorize, suggest, influence, encourage and render possible. They can also block, forbid, allow or withhold permission. Key tenets of Actor Network Theory (ANT) suggest we can view the market context for SDPs as a society, or service ecosystem (Wieland, Polese, Vargo and Lusch 2012), 
in which institutions, technological "things" and consumers (collectively, "actants") are all equally, and causally, efficacious (generalized symmetry; Callon 1986). Each actant exists within a host of interweaving hybrid relationships - smart product and customer; customer and community; community and institutions; institutions and commerce - representing a heterogeneous social network. The persuasive potential designed into SDPs, however, heightens the transactional possibilities for the technologies concerned, thus furthering technology's reach. Smart products generally (and SDPs particularly) therefore, distinguish themselves as a category either distinct within or separate from the SST. Thus, the overtly sociological and ethical parameters that apply demand a diffusion study framework that directly acknowledges such concerns, a task we undertake in the sections that follow.

\section{Framework development: A longitudinal perspective}

Our objective now is to develop a framework for exploring/ explicating the dynamics of SDP engagement. First, we develop our model in the horizontal, with Fig. 2 summarizing key longitudinal phases. Second, we develop this vertically to address cross-sectional issues of interest. The following narrative explains the first of these two phases of model development.

In studies of innovation, diffusion often describes a condition of the many. It signifies public rather than individual acceptance (Rogers 2003). At the personal level adoption denotes a similar state, and for technology the process by which this might be achieved has been styled appropriation (Ilmonen 2004). Gram-Hanssen $(2008,2011)$ explicates this as a broadly linear sequence that begins with internalization, or accepting that a proposed consumption object will play some role in one's life. This is then followed by cognitive adoption, a phase during which we introduce the new object into our lives or consider how we intend it to feature in the way we do things. Following cognitive adoption is configuration or the procedure for integrating the artifact into context; and, finally, there is externalization, or the act of sharing with others the role for which the thing has been sanctioned. Stages of appropriation can be readily associated with ideas discussed earlier - the evolving nature of customer engagement, and notions of hybridization and imbrication derived from Actor Network Theory and sociomateriality. In terms of SDP embeddedness appropriation leads to the social linking of relationships and context.

Taken individually the top three rows of Fig. 2 illustrate diverse ways for describing the introduction of a new technology into the lifeworld of a consumer. Coincidentally, their parallel arrangement identifies similarities between the concepts concerned. Taken together, and viewed in transverse (e.g., $\mathrm{X}-\mathrm{X}$ on Fig. 2), a more complex view of each/any point in the horizontal can be obtained, thus providing for a more complete understanding of the conditions for engagement that apply. However, the model as described thus far lacks both a unifying core and defining characteristics that distinguish this as a framework for smart product engagement. Further, reference to the first two elements of the Evolving Hybridization continuum identifies concepts that we have not yet addressed. To attend to these discrepancies, we next review a further range of ideas arising from disciplines discussed thus far. In the process, and drawing on a tradition for applying alliterative mnemonics to contexts of marketing interest (e.g., Constantinides 2006), we outline a continuum of events we term proposal, project, practice, pause.

\section{Proposal}

Before project or practice can ensue, the consumer must be aware that an object of engagement exists. Some means of proposal, either internally or externally generated, must intially occur. Reference back to SDL and the marketing literature suggests that the proposal - in the case of smart meters for example, the pitch from government and energy suppliers; for Amazon's Echo, TV advertisements; for a health monitor, recommendation from a doctor - would correspond with the notion of a value proposition (see Foundational Premise 7; Vargo and Lusch 2004). This, argue Frow and Payne (2011), denotes the benefits a supplier delivers to a customer and that coincidentally are considered to be of value. More pertinently however, value propositions might be seen as actor-to-actor invitations that are focused on the provision of mutually beneficial service (Chandler and Lusch 2015). Such invitation will invoke a bundle of attributes that the supplier would hope to deliver and would hope the customer finds to be of value.

Holttinen (2010) suggests that value is tied to practices, not offerings, and that understanding the meaning structures of practices is essential to the framing of effective propositions (Skålén, Gummerus, von Koskull and Magnusson 2015). Considered this way, the value proposition concept provides an explanation for how relationships among customer, supplier, market offering and practice might emerge. Understanding, though can be further enriched by reference to cognitive psychology. Adopted also by those interested in the relationship between humans and the material, the notion of "affordance" can readily be associated with that of the value proposition. First discussed by Gibson (1979) affordances are "the possibilities for action called forth by it to a perceiving subject." (Fayard and Weeks 2007, p. 609). Thus, doors afford entry and exit; a laptop affords searching and word-processing; a motor car affords travel.

These potentialities are "value creation opportunities" (Norman 1988), and the collective affordances of an entity effectively constitute the value proposition pertaining to it. Object affordances trigger the potential for action/value- 
Fig. 2 A composite model of SDP engagement
Engagement, appropriation and hybridization increase iteratively and coincidentally to enhance embeddedness. Together, these characterize progress along the proposal-to-project continuum. X-X represents any point along this continuum and demonstrates how all longitudinal elements cumulatively explicate the point concerned.

\begin{tabular}{|l|c|c|}
\hline \multicolumn{3}{|c|}{ Deepening Engagement (leads to psychological embeddedness) } \\
\hline Cognitive & Cognitive + Behavioral & $\begin{array}{c}\text { Cognitive + Behavioral + } \\
\text { Attitudinal }\end{array}$ \\
\hline Identification & Attention, enthusiasm & Absorption and interaction \\
\hline
\end{tabular}

\begin{tabular}{|c|c|c|c|}
\hline$\longrightarrow$ & \multicolumn{2}{|c|}{ Appropriation (leads to social embeddedness) } & $\Rightarrow$ \\
\hline Internalization & Cognitive Adoption & Configuration & Externalization \\
\hline
\end{tabular}

\begin{tabular}{|c|c|c|}
\hline $\begin{array}{c}\text { Perceived } \\
\text { Affordances/Constraints }\end{array}$ & $\begin{array}{c}\text { Customization, and } \\
\text { evaluation/realization of } \\
\text { Affordances/Constraints }\end{array}$ \\
\hline PROPOSAL & PROJECT \\
\hline
\end{tabular}

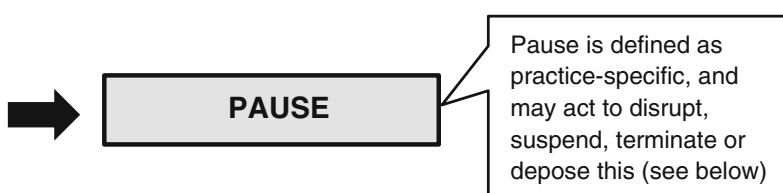

\begin{tabular}{|l|l|l|l|}
\hline $\begin{array}{c}\text { Pause 1 } \\
\text { Pause for thought } \\
\text { (disruption) }\end{array}$ & \multicolumn{1}{|c|}{$\begin{array}{c}\text { Pause 2 } \\
\text { Temporary pause } \\
\text { (suspension) }\end{array}$} & $\begin{array}{c}\text { Pause 3 } \\
\text { Permanent pause } \\
\text { (termination) }\end{array}$ & $\begin{array}{c}\text { Pause 4 } \\
\text { Practice without } \\
\text { purpose (deposition) }\end{array}$ \\
\hline $\begin{array}{l}\text { A momentary hesitation } \\
\text { in practice }\end{array}$ & $\begin{array}{l}\text { Temporary but } \\
\text { purposeful cessation of } \\
\text { practice. At some future } \\
\text { point practice may be } \\
\text { resumed. }\end{array}$ & $\begin{array}{l}\text { Purposeful and } \\
\text { permanent suspension } \\
\text { of practice. Practice will } \\
\text { never be resumed in its } \\
\text { original form. }\end{array}$ & $\begin{array}{l}\text { Practice is purely a } \\
\text { "regularity" - a habit or } \\
\text { routine that is } \\
\text { performed at low levels } \\
\text { of proprietorial } \\
\text { engagement }\end{array}$ \\
\hline
\end{tabular}

creation in the subject's mind, and the value derived accrues via a process of negotiation between all actors within the pertinent service ecosystem. As Fayard and Weeks (2014) suggest, a recognition of affordance allows an observer to explain how the material shapes action. Affordances, therefore, assist goal-oriented activity and consequently "allow" those activities to emerge (Markus and Silver 2008). Resources - on both customer and supply side - can also act to constrain, and can consequently also interrupt or disturb action. Materiality exits independently of people, but the affordances and constraints this offers do not (Hutchby 2001). It is consequently these - rather than technologies themselves - that determine the extent of engagement that is likely to exist. We will return to affordances later.

\section{Project and practice}

Interestingly, the notion of engagement is to be found in theories of practice - also strongly associated with sociomaterial study. Practices, suggest Schatzki (1996), are the fundamental unit of analysis for social phenomena (e.g., experiences, actions, activities). These can be imagined as either dispersed or universally performed (e.g., explaining, describing, following rules - "knowing how"); or as disciplinarily integrative (e.g., farming, cooking and attending meetings, for example). These latter comprise combinations of dispersed practice, or "knowing what." Reckwitz (2002) suggests that practices give the social world its visible orderliness and allow us to understand the everyday roles of both human and non-human 
objects. He defines practices as activities that are routinized, elementally complex, and integrated. In this sense both what is to be done and why it is to be done are culturally embedded. Schatzki's (1996) teleoaffective structures - ends, beliefs, motivations, purposes - are key components of practice and to a certain extent goal-oriented. Goals though, are not personally defined, but are normatively and culturally constructed and limited by practical intelligibility (the capacity to make sense of an opportunity, event or activity).

Although sociomateriality, ANT and practice theory were developed primarily for organizational settings, relevant ideas have more recently transferred beyond the office and into other domains, including the home (e.g., Hand and Shove 2007; Shove and Pantzar 2005; Shove, Watson, Hand and Ingram 2007). Following Warde (2005), the notion of consumption-as-practice has also gained momentum and has moved on from the relatively niche area of consumer culture and now informs critical thought at the periphery of the marketing mainstream (e.g., Goulding, Shankar and Canniford 2013; Schau et al. 2009; Skålén, Pace and Cova 2015). A broad consensus is developed here that posits practice as the context for co-creating value and, ipso facto, for furthering engagement (Storbacka et al. 2016).

Practices are conceptually associated with both routine and habit, are emergent and continuously updated over time (Warde 2005). In the context of SDPs, it is evident that engagement is likely to increase coincidentally as practice emerges and hybridization evolves - assuming that relevant practices and the technologies they are associated with are themselves "engaging" (see later). The transitional process of engagement connecting new and habitual practice allows either integration of material entities into existing practice or perhaps the construction of a new practice. Hand and Shove (2007) suggest that the process of domestication permits home artifacts to move from novelty to normality, with their use becoming routinized rather than exceptional - or, as suggested earlier, made independent of conscious reflection.

Campbell (2005) further identifies that objects will be appropriated differently in diverse social, cultural and practical settings. Thus he suggests we can consider each individual as a craft consumer, every one of us personally customizing the appropriation process to suit our own world of meaning especially at the outset, before habit or routine is established. For each person, initial experiences might be collectively considered a project - "planned, temporally bounded episodes or sequences of activity resulting in an observable outcome" (Watson and Shove 2008, p. 9). Here it is the normalized outcome that is most appropriately considered as practice. This, we believe, is likely to apply particularly for SDPs, where motivation to engage will be less certain or assured than for a familiar, more conventionally configured domestic convenience.
For Watson and Shove (2008) however, a project is considered an alternative to practice, in that the first is temporally bounded and the other ongoing. We believe though, that project can be interpreted as a stage that precedes practice. Considered as sequential rather than parallel activities, project and practice can be seen as distinct stages of developing engagement. We acknowledge project as a temporarily constrained phenomenon, but for our purposes suggest it is initiated through acceptance of a proposal and finished when it emerges into practice. Project is effectively a rehearsal and practice a performance, both related to something that is new and also potentially ambiguous as to benefit. Schau et al. (2009) associate practices with apprenticeship or learning, but we suggest they differ: it is projects that operate like apprenticeships and as a consequence precede practice. Only after trial, preparation and accommodation (which collectively we call project) does practice render action reproducible and repeatable. Therefore, we suggest project and practice be considered separate events.

\section{Pause, and summary}

And finally to pause. Other factors, including those associated with customers - free will, awareness, capability and capacity (Fayard and Weeks 2007) and self-efficacy too (e.g., Wang et al. 2013) - will help determine the degree to which affordances can be realized. And referring back to a captalogical/persuasive perspective on technology we can see that affordances (and constraints) can be multi-directional. SDPs afford opportunities for customer action, but coincidentally afford opportunity for action further back through the supply chain. In turn these reverse affordances may be the triggers that prefigure suspicion in consumer minds. Thus affordances for one stakeholder may be a form of constraint for another, meaning there is a tension within the SDP ecosystem that needs to be resolved or at least understood.

The issue here for supply-side stakeholders is whether engagement outcomes (or practices) conform to what was initially proposed or intended. Imbrication implies full assimilation of all resource integrators to create a viable and ongoing social system. In our account this means agency, social structure, material relations and culture are all emergent features of human life that are ontologically irreducible. Imbricated relationships though, are just pinned into place (Shove 2003); they remain in flux, and each hybrid component will continually attempt to assert its independence. For the customer any engagement doubt will be strongest when constraints outweigh affordances, perhaps leading to a "pause," or a reconsideration of, or reflection on, the original hypothesis. And also perhaps to the proposal on which it was based and the context in which it is experienced.

Pause, we suggest, will intercede into practice if and where engagement fails to convert into absorption and interaction, or 
where it is attitudinally unstable. This is represented in Fig. 2 as both/either a point or period of reassessment. This is an opportunity for determining - either sub-consciously or via return to conscious reflection - whether practice should be continued, discontinued or maybe sustained, but at some sub-optimal level. Perhaps undergone as an anesthetic, rather than aesthetic, experience (Dewey 2005/1932). Pause is therefore considered a behavioral condition that might be fleeting, temporary, or permanent. Consideration naturally precedes and characterizes project (the customizing/rehearsal stage) but pause, or re-consideration, is specific to practice. Following any momentary hesitation in practice (type 1, Fig. 2) the pause could be transitory - as reflection fades and practice is renewed (type 2) - or permanent, as reflection turns to disaffection (type 3 ). This could subsequently transform into rupture, alienation or divorce, meaning the SDP is purposely ignored or even disconnected. Pauses 1-3 therefore, occur at (or are) "situations of disturbed equilibrium" (Dewey, in Gouinlock 1976) initiated by doubt. Pause could occur any time, but types 1,2 and 3 would most likely arise at some personally or socially determined occasion where the possibility of continuity is brought into question.

Alternatively, pause could manifest itself as practice without purpose, or mere regularity (Rouse 2001), playing no effective role in the normative practice of SDP engagement (see pause type 4, Fig. 2). We note that Warde (2014, p. 14) suggests, "For most folk, most of the time, most of daily life occurs in a state of distraction. Habit and routine are normal - the default mode of engagement in the world." But we also discern that distraction evokes the lowest, least efficacious levels of engagement. Furthermore, the lack of conscious awareness that characterizes practice (Torriti, Leach and Devine-Wright 2011) and which is the default aim of SDPs, can also become an obstacle. Thus practice may be or become an impediment to externalization and could limit imbrication. Consequently, we need to distinguish practice that is engaging - in an involving/absorbing sense - from practice that is mere regularity. This latter, characterized by torpor, we identify as disengagement, with pause 4 its manifestation. Thus, although consumer and technology may appear entangled, their relationship may be little more than a "dead" marriage (Witztum, Van der Hart and Friedman 1988), a meaningful relationship in name only. Consequently, benefits may be at least sub-optimal, inconsequential, or at worst, non-existent.

Figure 2 illustrates a four-stage continuum, the first three drawing vertically upon related ideas and the fourth representing ways in which the third might be disturbed. Stage 1 is Proposal, when an outside agency suggests/ promotes SDP adoption. At this point the consumer internalizes the proposition and begins to make sense of it by hypothesizing potential affordances, constraints and likely collective effect. Once a decision to adopt is made, the consumer begins to engage behaviorally with the technology and provisionally to configure it in terms of both location and deployment. Here, engagement aligns with Project (stage 2), as consumers begin to understand how they and the technology will, or can, work together. The consumer - in partnership with the SDP concerned - customizes this configuration to fit their specific sociocultural context, gradually realizing perceived affordances and constraints. At Stage 3 engagement achieves the status of Practice, meaning hybridization is potentially complete - with the conditions for technology, consumer and social/physical context to be fully imbricated, in place.

Ideally, engagement and adoption will now be attitudinal as well as cognitive/behavioral, and consumers should be happy to externalize to others the meaning the technology has for their life. Furthermore, at Stage 3 the potential for psychological, social and physical embeddedness is achieved. However, Pause could interject as a corrective to Stage 3. This could disrupt (pause 1; pause 2); suspend and follow (pause 3); or, perhaps, supplant (pause 4) practice. These final pauses, each equally damaging, constitute a special challenge to marketers. Installation/supply of a SDP will not automatically lead to its effective use, and "embedding" will not inevitably occur.

\section{Framework development: A cross-sectional perspective}

\section{Value and personal advantage}

If marketers are to give equal regard to every phase of engagement, a means for expressing consumer reaction along our continuum is clearly required. To address this, we add a vertical element to our model representing a set of consumptionrelated criteria that focus on both the positives and negatives associated with SDP engagement. Warde (2005) suggests consumption is an aspect of all (deliberative) practices, but it can be argued that its primary purpose is not to support the practice itself but rather to support outcome. It has already been demonstrated that, from a marketing perspective, instead of representing per se the fundamental unit of analysis for social phenomena, practice can be considered one aspect of a complex engagement trajectory. Consumers are continuously pursuing, or wish to sustain, a preferred outcome; something that we term personal advantage (Woodall 2003). The next phase of our discussion therefore, completes our SDP research framework (see Fig. 3) and explains how and why we choose the term personal advantage, and how this derives from a review of the associated phenomenon, consumer value.

Personal advantage is an individually perceived consumption outcome, but does not necessarily represent some form of rationally determined end. As previously noted, Schatzki (1996) suggests that teleological aspects of practice are not absolute but are transient, emergent and amorphous. They are appreciated day-by-day, or even minute-by-minute, and 


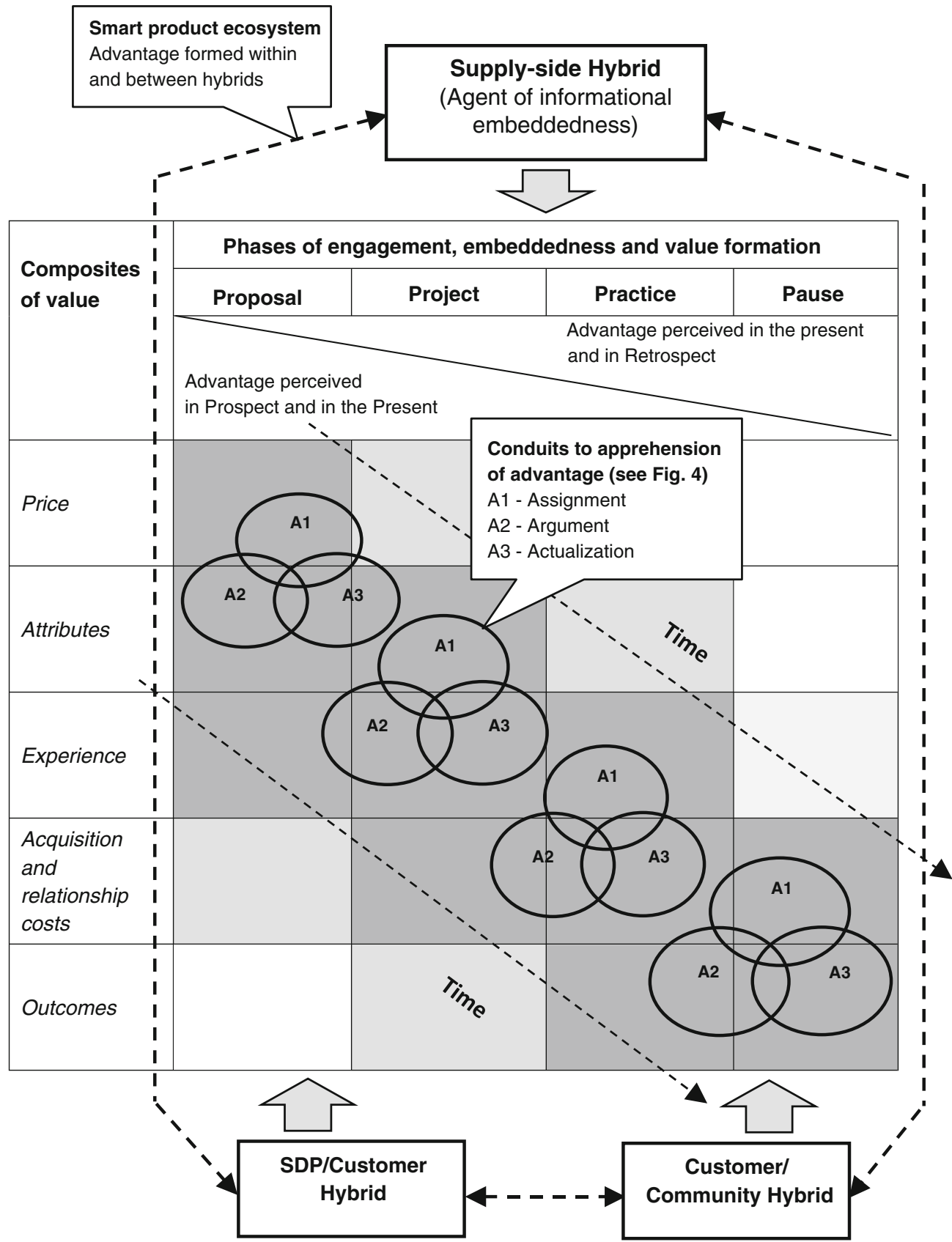

Note: Advantage (or disadvantage) is an aggregate positive or negative perception resulting from an individual's conscious or unconscious processing (or trade-off) of consumption-related cost/benefit information and/or experience. It is closely related to value, but it is an umbrella term for and outcome that reconciles and/or aggregates different positions and perspectives on value.

Fig. 3 A framework for exploring SDP engagement

are realized both cognitively and emotionally. In such a context we argue that perceived personal advantage provides a more relevant unit of analysis than does practice. This is because, at any point in the engagement continuum, it represents the manifest locus of subject, object and cultural/ socioeconomic context.

Perceived personal advantage is closely associated with perceived consumer value. In many ways it is synonymous with consumer value but is specified differently. In the marketing literature consumer value represents what is positive only, and is used to describe many different conditions. We prefer the term consumer advantage because (a) this transcends the polysemic nature of the word 'value' and (b) it can readily be attributed in the converse (disadvantage). We define perceived personal advantage/disadvantage as an aggregate positive or negative perception that results from an individual's conscious or unconscious processing of consumptionrelated cost/benefit information and/or experience. In the 
following discussion we draw on the value-related literature to demonstrate this. We show also how the notion of advantage can help to refine and extend our framework for understanding SDP engagement.

\section{The case for trade-offs}

The Service Dominant Logic (Vargo and Lusch 2004) and later Customer Dominant Logic (e.g., Grönroos and Voima 2013; Heinonen, Strandvik, Mickelsson, Edvardsson, Sundström and Andersson 2010; Tynan, McKechnie and Hartley 2014) literatures, focus on the co-creation and/or formation of value. Also on the economic concept of value-in-use (also expressed as value-in-experience, value-in-context and most recently, value-in-the-experience and value-in-life). Here value is framed heuristically as an abstract consumption outcome that increases general well-being, and in that literature its composition is only rarely (e.g., $\mathrm{Ng}$ and Smith 2012) contemplated. Here there is no shortage of extant commentary on the relationship between value and practice (e.g., Ellway and Dean 2016; Helkkula, Kelleher and Pihlström 2012; Holttinen 2010,2014 ) but this most frequently applies again, in the aggregate, thus neglecting structure and constitution.

However, the broader consumer behavior literature represents value not as a single unifying concept, but as a multicompositional domain premised on associated but differing ideas. These coalesce around different arrangements of what we term the composites of value. For example, means-end chain logic (Gutman 1982) assumes the attributes of market offerings provide the potential for value, and that these are transformed into meaningful outcomes via experiences. Other perspectives view value as the outcome of a trading-off process whereby customers weigh the relative effects of benefit and sacrifice ("get" and "give"). Here optimum value occurs when positive difference is greatest. At its most basic (e.g., Gale 1994; Oh 1999; Ostrom and Iacobucci 1995), this branch of the literature considers just attributes and price, the consequence expressed as "value for money." Other trade-off perspectives however (Grönroos 1997; Heskett et al. 1997) identify that "give" components go beyond price, and incorporate both acquisition costs (time, effort, maintenance) and psychological costs (e.g., fear and anxiety). As a result, some later contributions (e.g., Mayr and Zins 2012; Ruiz, Gremler, Washburn and Carrión 2008; Woodall, Hiller and Resnick 2014) have adopted a wider perspective on the benefits/ sacrifices relationship than that which focuses purely on value for money. These look to compile a more complex/granular account that incorporates elements of the means-end approach.

The co-creation literature suggest consumer value is idiosyncratic, phenomenological, contextual and meaning-rich (Vargo and Lusch 2008). Also, that it comprises affective, social, economic, cognitive, physical, psychological and biological dimensions (Heinonen et al. 2010). Co-creation/ formation literatures are therefore seen to offer a more phenomenologically authentic take on value than those concerned with trade-offs. These latter, associated with neo-classical approaches to consumer behavior, are said to endorse rational foundations for choice (Gummerus 2013). However, as Rodríguez et al. (2006) suggest, trade-offs often occur without either pre-meditation or even awareness of their occurrence. Malafouris (2013) similarly argues that all forms of sensemaking have non-cognitive aspects - suggesting coincidentally, that "the material" has a hitherto underappreciated impact on the sense-making process. Further, a trade-off perspective helps us recognize that value, or personally perceived advantage, can be appreciated as positive, neutral, or negative.

We express the way that people process value/advantage in consumption as a wrangle. We posit this as a complex internal dispute between multiple agendas striving for congruence in overlapping contexts. According to neurologists the brain is a highly distributed and self-organizing system of neural networks that functions on the basis of learning and adaptation (Kazmina et al. 2014). It deploys various and multiform feedback loops. A wrangle, therefore, is thus best characterized as a mechanism for abductive reasoning, and designates tradeoffs also as idiosyncratic, cognitive/affective and contextual.

\section{The nature of trade-offs}

The trade-off tradition focuses primarily on benefit and sacrifice, but if "to wrangle" implies a networked rather than binary approach to sense-making there must be more to it than this. Our thesis therefore, is that the benefit/sacrifice dyad is just one of three epistemologically relevant and dichotomous constructs nested within the category, personal advantage (Fig. 4).

Benefits and sacrifices are essentially inputs to, and outputs of, a trade-off process that can be named, listed, described and

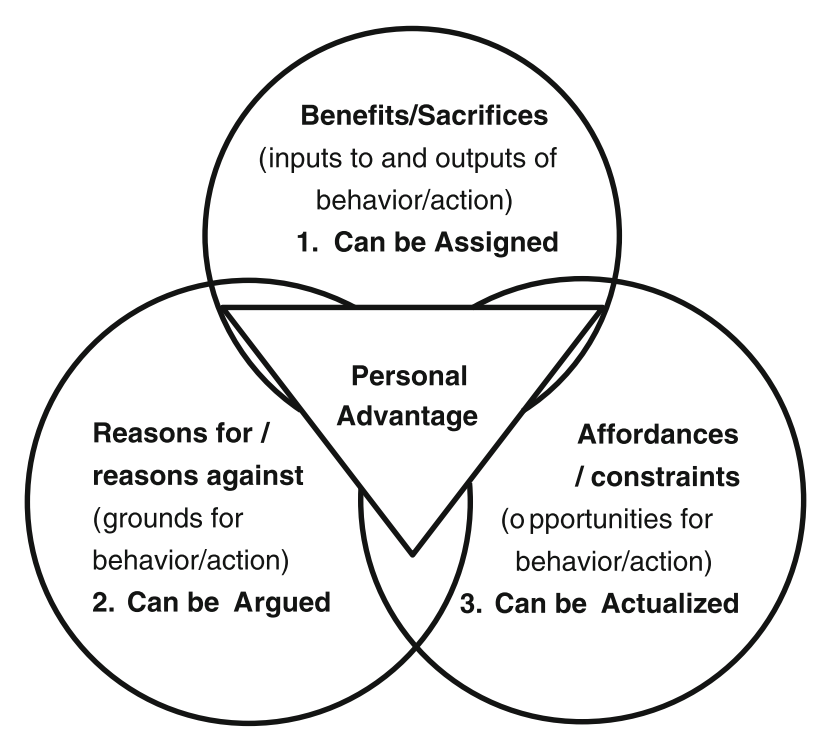

Fig. 4 Constructs of Personal Advantage/Conduits to value apprehension 
assigned (this is what went in, and this is what came out). Consequently, these can be readily articulated via the previously noted composites of value and remain key to understanding. However, we note a recent strand of TRA-related research (e.g., Claudy et al. 2015) where, based on Westaby's (2005) Behavioral Reasoning Theory (BRT), both "reasons for" and "reasons against" are given as key antecedents to innovation diffusion. We are convinced by their suggestion that "reasons" play a role in the wrangling process (they have causal efficacy) and that both continuance and defection will result partly from consciously/sub-consciously rehearsed arguments.

These arguments may be played out contemplatively, conversationally, or even unconsciously, with inputs to a particular course of action being balanced and accorded weight. This doesn't imply that decisions are entirely reasoned, but does suggest that grounds for (and against) specific decisions will be accounted for in perceptions of personal advantage. Consumers will wish to defend, both to themselves and to others, what they want to do (Westaby 2005). Concerns about data security and social status, for example, are much more likely to be articulated as issues of debate than they are, say, as issues of classification, quantity or quality. "Reasons for" and "reasons against" therefore, we suggest, represent an additional conduit to apprehension.

Lastly, we return to Gibson's (1979) notion of affordances and to the limiting impact of constraints. Determining the ways in which consumers understand both their relationship with technology and the extent to which they believe it impacts their personal/social being aids our account of SDP engagement in two ways. First, this explicitly acknowledges the pervasive effect of the material. Second, this adds further depth to considerations of personal advantage, and recognizes the interplay between grounds for engagement (and disengagement) and the essence of the technology itself. Here we note inter alia, that not just SDPs themselves, but also related and performative associations (advertisements, exhortations, etc.; Cochoy 1998) will help inform a customer's capacity for action. We argue consequently, that to identify how sources of value impact customer meaning we need to access multifarious insights into value formation. In our model therefore, conduits to apprehension are collectively represented via (1) assignment, (2) argument (reasons for or reasons against) and (3) actualization (physical and/or psychological and/or economic realization of affordance and constraint).

\section{An extended model of SDP engagement}

Drawing on positions taken thus far we suggest a multiform structure that conceptually maps pertinent aspects of engagement and embeddedness that should be of interest to marketers. Our full model (see Fig. 3 further above) depicts: engagement phases, composites of value (that inform perceptions of advantage), and key hybrids that configure the SDP ecosystem. A fourth element (conduits to the apprehension of advantage) is represented by a triform sub-framework that nests within the broader model structure and addresses the routes by which composites of value/advantage might be constituted within the consumers' sphere of understanding.

Proposal, project, practice (and, potentially, pause) represent phases of engagement where subject/object hybrid relationships fluctuate, as familiarity with, or expertise in, SDP endeavor emerges. At each phase (though we posit a progressive/recursive, rather than an episodic/linear, continuum) the consumer will be both object of and party to an ongoing sensemaking process. This acknowledges the causality of both human and non-human entities. Huber, Lynch, Corfman, Feldman, Holbrook, Lehmann, Munier, Schkade and Simonson (1997) suggest that value is viewed in prospect, in the present and also in retrospect. This means that all composites can - potentially, coincidentally, and to varying degrees feature at any given time in the customers' estimation of value. We thus argue that each of the horizontal phases will be differently informed by varying and overlapping perceptions of value, or advantage. Thoughts at proposal for example, are likely directed to the present and future, while practice and pause invoke the present and the past. Pause may occasion a re-imagining of the value proposition and consequently of likely outcomes.

The composites of value are drawn from the preceding discussion on value trade-offs and are: price (what, if anything, is given up directly to the supplier to allow use of the SDP); attributes (the features, properties and qualities of the SDP and its attendant ecosystem); experiences (events occurring in association with, or having association to, the SDP, and that leave an impression); acquisition and relationship costs (anything that has to be given up in order to sustain and/or maintain experience with the SDP and its ecosystem); and, outcomes (long-, medium- and/or short-term consequences of association with the SDP). Price and costs however are not necessarily money-based, and comprise economic, psychological, physical and time-related components.

Although these last are organized in the vertical, we note a temporal connection between composites of value and phases of engagement. For example, the consumer is most likely to become aware of price and attributes at the proposal phase, and will only encounter experiences and acquisition/ psychological costs after the proposal has been endorsed (during project and practice phases). By contrast, full realization of outcomes is most likely to occur at practice and pause ("value promises are redeemed in use," Holttinen 2010, p. 96). Consequently, we illustrate perception of advantage occurring in the diagonal rather than the flat and represent this as a transverse band. At any point in the diagonal, advantage will be perceived primarily as a function of whichever vertical and 
horizontal element it is most closely associated with. But perceptions will also be influenced by both proceeding and preceding elements, in both axes, according to the strength and proximity of each. Thus the band is wide and progressively shaded.

The service ecosystem will also determine how advantage is perceived. Here we suggest that a supply-side hybrid (a convergence of institutional forces supplying/ monitoring the SDP), a customer/SDP hybrid (the consumer at home) and a customer/community hybrid (the consumer and his/her social mélange) will dominate. Clearly, there will be many other system components at play (see Edvardsson, Kleinaltenkamp, Tronvoll, McHugh and Windahl 2014) but for expedience our model emphasizes those hybrids that we most readily identify as integrators of resource.

\section{Discussion and key theoretical positions}

Recent innovation diffusion studies in the marketing field (e.g., Claudy et al. 2015; Laukkanen 2016; Patsiotis, Hughes and Webber 2013) suggest that a small number of research models dominate (e.g., Theory of Reasoned Action [TRA]; Technology Acceptance Model [TAM]). However, there is no clear consensus on the most relevant factors impacting diffusion or the best way of determining how these might be defined. This is unsurprising given the wide array of potentially causal variables apparent to students of consumer behavior, the diverse demographic and psychological nature of consumers, and the infinite variety of innovation objects that present for attention. The recent emergence of SDPs adds to this variety and complicates the challenge.

The evolving literature on SDPs exists overwhelmingly on non-marketing platforms, comprising largely sector- rather than discipline-focused studies (e.g., computing, healthcare, engineering, and energy management). These tend to focus on what can be achieved through SDPs and how these might be designed, configured, applied or managed. Diffusionrelated studies are fewer but increasing (e.g., Buchanan, Banks, Preston and Russo 2016; Lazar et al. 2015; Portet, Vacher, Golanski, Roux and Meillon 2013; Tseng, Hsu and Chuang 2013; Yang, Lee and Zo 2017). Given their largely applied nature though, these tend to rely on established theoretical frameworks and SDP-specific theory development is slow to emerge.

Our proposed framework acknowledges this and is focused specifically on establishing the extent to which consumers perceive either advantage or disadvantage in their SDP relationships. The framework is premised on a range of key theoretical positions which characterize the distinctive nature of our approach. Conceptually, our study draws on two diverse areas of thought that surfaced within the field of consumer behaviour a little more than a decade ago. These are Service Dominant Logic (SDL) and organizational sociology. Recently marketing scholars have sought to explore how these connect (e.g., Akaka, Vargo and Lusch 2013; Löbler 2011; Skålén and Edvardsson 2016; Vargo and Lusch 2016), primarily invoking structuration theory and practice theory. Less frequently combined, though, are studies concerning SDL and concerns of a social/material nature. This leads to our first theoretical position.

There is an emerging weight of theory that now posits structural, material, human and synthetic entities as inter-reliant. Callon, Law and Latour's Actor Network Theory, Orlikowski's Sociomateriality, Shove's Theories of Domestication, and Malafouris's Theory of Material Engagement have emerged to represent a collective and increasingly normalized logic. The smart home we suggest, is just the latest context in which people and technology are seen to combine. First there was the office and more recently the servicescape (Bitner 1992) where SSTs have become indispensable to service experience. We acknowledge this evolved imperative and our framework responds to a call (Campbell et al. 2014) for "the material" to be given due causal regard in research concerning one specific SDL axiom: resource integration.

Academics have recently grappled with notions of how social beings make sense of their environments; how patterns of life emerge, stabilize and give meaning and shape to society. Ascendant theories of practice hold that tacitly determined routines rather than individuals should be the fundamental focus for research. Via Bourdieu, Giddens, Schatzki and Reckwitz and with roots in the philosophy of Heidegger and Wittgenstein (Halkier, Katz-Gerro and Martens 2011) practice theory has taken hold. But by elevating the status of structure, culture and routine, consumption-related reflection has been marginalized. Normative sociological perspectives applied in recent marketing studies (e.g., Holttinen 2014) have consequently led to the view that practice begets value. Thus practice becomes the focus of attention. We argue that the practices that emerge to accommodate novel and relationally advanced products (such as SDPs) are those that are perceived to offer the best personal advantage. Thus, for this as yet unfamiliar consumption domain the factors contributing to perceptions of advantage should warrant primary attention - at least from marketers. Bonnington (2015) suggests that human reflexivity is essential to the shaping of practice, and we concur. Our second proposition therefore, is that while the material helps constitute both, to large extent the consumer performs SDP practice and not the reverse.

We recognize the role that routines play in the embodiment of social life but do so by acknowledging both their theoretical and dispositional meaning. This allows us to separate the impact of practice from the role of practice and to consider this as a duality. On the one hand we posit practice as an engagement 
phase that follows from introduction of and rehearsal with a product. On the other hand, we see practice as a habitual condition that can vary from fully engaging to disengaging. Therefore, a mnemonic device is used, recalling other marketing tenets (see Constantinides 2006) and suggesting that it incorporates other largely unexplored consumption conditions. Thus, in addition to proposal and practice we introduce project and pause.

The first (project) acknowledges that both the potential and function of a newly presented product should be fully understood and rehearsed before effective practice can occur (especially important for a product category that requires full embeddedness to become effective). Pause, as both disruption to and suspension of customer commitment and loyalty, has already been extensively explored, but we also posit this as a condition that can supplant continuance. Pause, defined as "practice without purpose," is applied because of its particular relevance to SDPs. For products that contribute to life experience rather than service experience, the possibility of beginning as or deteriorating into torpor is a real danger. Our third proposition therefore, is that SDP-related marketing research should not just consider acquisition as one key area of study and practice as another, but should distinguish the latter as comprising three distinct phases of interest.

Our fourth proposition is that perceptions of advantage derive via a complex set of parameters that should be considered both separately and in concert. By this we mean that although advantage will ultimately appear as a gestalt (an articulated whole comprising distinct parts that are capable of appreciation; Smith 1988) we need to know how this accrues and is made manifest in the context of personal reflection. Given the compound nature of relationships among people, society, organizations and SDPs, we need to take account of the widest array of those "parts" that can be appreciated. Engagement at any stage along the proposal-to-pause continuum is judged on the basis of cumulatively observed evidence of psychological, social and physical embeddedness. At any point there will be a corresponding measure of perceived advantage that derives from the strength and proximity of both longitudinal and cross-sectional framework characteristics.

In turn, our fifth proposition suggests this perceived advantage forms because of the collectively weighted outcome of assignations, arguments and actualizations - both consciously and sub-consciously directed towards the gestalt view. Of especial relevance to the SDP domain we emphasize the need to explore the dichotomous effects of both affordances and constraints as well as reasons for and against both adoption and continuance. The first of these acknowledges the causality arising from an individual's relationship with the material; the second accedes to a need to understand the issues of internal debate that help form either positive or negative sentiment. Formal diffusion models (e.g., UTAUT, TAM, TBA) draw conclusions by measuring the strength of attitudinal/ intentional antecedents to acceptance or rejection. However, we have identified critiques that suggest there is little consensus as to what these might be. By contrast we address the common factors that underlie and structure these attitudes and intentions, and draw attention primarily to the interplay of advantage and engagement.

Our sixth proposition relates to how actors are characterized in technology diffusion marketing studies. These normally posit the customer and the technologies they use as ontologically distinct. Consequently, these are viewed primarily as protagonists of essentially different quality and significance. We suggest that as technology becomes increasingly familiar - as computer-mediated environments are more the norm and less the exception - product engagement will be the least difficult challenge to overcome. In smart homes, the technology product (SDP) and the consumer will become one (the customer/SDP hybrid), and residents will blend to become smart communities (the customer/community hybrid). The major protagonist then becomes the supply-side hybrid - that is, the agent of informational embeddedness; or in practical terms, suppliers' objectives and the Internet of Things.

Full union with this final class of embeddedness is the final hurdle for complete SDP engagement. For many SDPs in many smart contexts this will be easily overcome. But as the systems of distributed intelligence become more integrated, more extensive and - potentially - as much a channel for persuasion as they are for support or advice (see Fig. 1), then both consumers and communities will react. The danger is that as SDPs move more towards the right-hand side of Fig. 1, the more contentious will be those designed for hedonic purpose, and the less trustworthy will be those specified as transformational. Our seventh proposition is that this will be the primary ongoing challenge for SDP engagement.

\section{Conclusion and directions for further research}

Our framework contributes to an expanded view on innovations diffusion in the specific context of the smart home. Coincidentally we link with a vital principle of marketing thought that suggests value resides at its core (e.g., Drucker 1954; Vargo and Lusch 2004). The framework is complex and unlikely to submit to one approach to research. It can however, be "depunctualized" (considered manifest at any point; Latour 2005 ) to surface knowledge relating to macro, meso or micro concerns. The notion that we can move upwards to an understanding of social structures and coincidentally downwards to a more nuanced appreciation of individual actions and relationships offers the potential for a nested, multilevel model of causation (Little 2012).

We invite others to propose and trial new research instruments to help operationalize our ideas. Our framework does not demand either intensive or extensive methods of inquiry. 
In the field of innovations diffusion, there is room for both qualitative and quantitative research, so our framework encourages a methodologically liberal approach. Below we list some objectives for early research, and these will also help assess the theoretical positions advanced in this article.

1. Marketing researchers will want to know how, or if, particular SDP types or properties facilitate smooth transition from proposal, to project, and then to practice that has effective purpose. Similarly, which products/properties are mostly likely to engender pause - either by disrupting, suspending or supplanting practice. Characterizing those customers most likely to succumb to the most damaging types of pause would be useful. Also, what affects their decisions? Evidence on factors contributing both independently and collectively to psychological, social and physical embeddedness will provide insight concerning theory propositions one, two and four.

2. Exploring the three suggested conduits to apprehension will help surface those personal, social, cultural and institutional factors that weigh most heavily on consumers' minds. Innovation diffusion researchers have noted that positive and negative constructs comprise different variables and, consequently, are causally distinct. Exploring issues of assignation, argument and actualization (both collectively and apart) will help advance relevant inquiry and provide support (or otherwise) regarding theory propositions three and five.

3. Marketers will also wish to know how SDPs help shape the behavior of society at large, and how these will inform both consumption and practice (or consumption as practice) beyond their immediate and intended effect. What will our priorities be in the new smart world, and how will the advantage (or disadvantage) that we perceive to arise from these shape our daily lives? Comparative examination of the impact of practice on perceptions of advantage, and of the impact of advantage on perceptions of practice will offer insight into theory proposition four.

4. It would be of special interest to marketing researchers to know how the supply-side hybrid impacts the process of appropriation and hybridization at each phase in the engagement continuum. Also how consumers apprehend the nature of the hybrid to determine which factors, and which contributing party or component, have the greatest positive or negative impact. Results will help inform the legitimacy of our concluding theory propositions six and seven.

5. Finally, recognizing that consumers and the artifacts with which they associate can be imagined in three distinct but complementary forms - dependent, independent and interdependent - means that marketing researchers can obtain a more granular and comprehensive perspective on those they wish to reach. Acknowledging that hybrids exist and that they interlink as well within a smart ecosystem (see dotted lines on Fig. 3) should also encourage marketing researchers to explore relationships among consumers, artifacts and significant others. Relevant research will further test our ideas regarding proposition six.

We believe also that our ideas and frameworks offer a gateway to further conceptual inquiry. Practice theory has now entered the marketer's vocabulary, but to date little thought has been given to how the tacit and routinized nature of practices impact the nature of habit-related marketing issues such as loyalty and commitment. Similarly, an approach to practice that perceives this coincidentally in abstract, dispositional and typological forms suggests direction for further inquiry into how practice might best be conceptualized for a marketing context. We also note that Gibson's ideas on affordance and constraint have thus far been applied primarily to contexts where material and synthetic entities are of most concern (e.g., engineering, information systems). Though customers are also subject to a wide array of environmental forces, and applying this theory in a consumption context may enrich an understanding of their behavior.

Other issues warrant further inquiry too. This article is focused chiefly on engagement, with embeddedness a supporting property (see Fig. 2). It would be interesting to take embeddedness as the primary focus and use this to direct further conceptual inquiry. In turn, this may reveal other areas of analysis that would benefit our understanding. Further (see Fig. 1), we began this article by locating intention and function as key variables for defining SDPtype objects. But other axes could be applied too, perhaps focusing on the nature and extent of the intelligence networks that underpin particular devices or systems, or on the multiplicity of function that each product performs. Lastly, we are struck by imperatives apparent in other disciplines that focus on smart contexts (sustainability, domestication, health, etc.) and the emphasis they place on behavior change. Perhaps the major contribution that marketing can make is to emphasize it is products that should be changed to accommodate customers, and not vice versa.

Open Access This article is distributed under the terms of the Creative Commons Attribution 4.0 International License (http:// creativecommons.org/licenses/by/4.0/), which permits unrestricted use, distribution, and reproduction in any medium, provided you give appropriate credit to the original author(s) and the source, provide a link to the Creative Commons license, and indicate if changes were made.

\section{References}

Ahn, M., Kang, J., \& Hustvedt, G. (2016). A model of sustainable household technology acceptance. International Journal of Consumer Studies, 40(1), 83-91. 
Akaka, M. A., \& Vargo, S. L. (2013). Technology as an operant resource in service (eco)systems. Information Systems and e-Business Management, 12(3), 367-384.

Akaka, M. A., Vargo, S. L., \& Lusch, R. F. (2013). The complexity of context: A service ecosystems approach for international marketing. Journal of International Marketing, 21(4), 1-20.

Åkesson, M., Edvardsson, B., \& Tronvoll, B. (2014). Customer experience from a self-service system perspective. Journal of Service Management, 25(5), 677-698.

Alam, M. R., Reaz, M. B. I., \& Ali, M. A. M. (2012). A review of smart homes-Past, present, and future. IEEE Transactions on Systems, Man, and Cybernetics, Part C (Applications and Reviews), 42(6), $1190-1203$

Ashton, K. (2009). That 'internet of things' thing, RFID Journal, June 22. http://www.Itrco.Jp/Libraries/RFIDjournal- that\%20Internet\% 20of\%20Things \%20Thing.Pdf. Accessed 15 July 2016.

Barakat, S. M. (2016). Internet of things: Ecosystem and applications. Journal of Current Research in Science, 4(1), 32-34.

Bitner, M. J. (1992). Servicescapes: The impact of physical surroundings on customers and employees. Journal of Marketing, 56(2), 57-71.

Bonnington, O. (2015). The indispensability of reflexivity to practice: The case of home energy efficiency. Journal of Critical Realism, 14(5), 461-484.

Botella, C., Riva, G., Gaggioli, B., Wiederhold, M. A., Alcaniz, M., \& Baños, R. M. (2012). The present and future of positive technologies. Cyberpsychology, Behavior and Social Networking, 15(2), 78-84.

Brodie, R. J., Hollebeek, L. D., Jurić, B., \& Ilić, A. (2011). Customer engagement: Conceptual domain, fundamental propositions, and implications for research. Journal of Service Research, 14(3), 252-271.

Buchanan, K., Banks, N., Preston, I., \& Russo, R. (2016). The British public's perception of the UK smart metering initiative: Threats and opportunities. Energy Policy, 91, 87-97.

Callon, M. (1986). The sociology of an actor-network: The case of the electric vehicle. In M. Callon, J. Law, \& A. Rip (Eds.), Mapping the dynamics of Science and technology: Sociology of Science in the real world (pp. 19-34). London: MacMillan Press.

Campbell, C. (2005). The craft consumer: Culture, craft and consumption in a postmodern society. Journal of Consumer Culture, 5(1), 23-42.

Campbell, N., O'Driscoll, A., \& Saren, M. (2014). Reconceptualizing resources: A critique of service-dominant logic. Journal of Macroeconomics, 33(4), 306-321.

Chandler, J. D., \& Lusch, R. F. (2015). Service systems: A broadened framework and research agenda on value propositions, engagement, and service experience. Journal of Service Research, 18(1), 6-22.

Chen, H., Finin, T., \& Joshi, A. (2003). An ontology for context-aware pervasive computing environments. The Knowledge Engineering Review, 18(3), 197-207.

Claudy, M., Garcia, R., \& O'Driscoll, A. (2015). Consumer resistance to innovation: A behavioral reasoning perspective. Journal of the Academy of Marketing Science, 43(4), 528-544.

Cochoy, F. (1998). Another discipline for the market economy: Marketing as a performative knowledge and know-how for capitalism. The Sociological Review, 46(1), 194-221.

Constantinides, E. (2006). The marketing mix revisited: Towards the 21st-century marketing. Journal of Marketing Management, 22(34), 407-438.

Dewey, J. (1976). Value and nature. In J. Gouinlock (Ed.), The moral writings of John Dewey (pp. 56-82). New York: Hafner Press.

Dewey, J. (2005/1932). Art as experience. New York: Pedigree.

Drucker, P. E. (1954). What is our business - And what should it be? In P. E. Drucker (Ed.), Practice of management (pp. 49-61). New York: Harper and Row.

Edvardsson, B., Kleinaltenkamp, M., Tronvoll, B., McHugh, P., \& Windahl, C. (2014). Institutional logics matter when coordinating resource integration. Marketing Theory, 14(3), 291-309.
Ellway, B. P., \& Dean, A. M. (2016). The reciprocal intertwining of practice and experience in value creation. Marketing Theory, 16(3), 299-324.

Fayard, A.-L., \& Weeks, J. (2007). Photocopiers and water-coolers: The affordances of informal interaction. Organization Studies, 28(5), 605-634.

Fayard, A.-L., \& Weeks, J. (2014). Affordances for practice. Information and Organization, 24(4), 236-249.

Fogg, B. J. (1999). Persuasive technologies. Communications of the ACM, 42(5), 26-29.

Frow, P., \& Payne, A. (2011). A stakeholder perspective of the value proposition concept. European Journal of Marketing, 45(1/2), 223-240.

Gale, B. (1994). Managing customer value: Creating quality and service that customers can see. New York: The Free Press.

Gangale, F., Mengolini, A., \& Onyeji, I. (2013). Consumer engagement: An insight from smart grid projects in Europe. Energy Policy, 60, 621-628.

Garcia, N. M., \& Rodrigues, J. J. (2015). Ambient assisted living. Boca Raton: CRC Press.

Gibson, J. (1979). The ecological approach to visual perception. Boston: Houghton-Mifflin.

Goulding, C., Shankar, A., \& Canniford, R. (2013). Learning to be tribal: Facilitating the formation of consumer tribes. European Journal of Marketing, 47(5/6), 813-832.

Gram-Hanssen, K. (2008). Consuming technologies-developing routines. Journal of Cleaner Production, 16(11), 1181-1189.

Gram-Hanssen, K. (2011). Understanding change and continuity in residential energy consumption. Journal of Consumer Culture, 11(1), $61-78$.

Gray, D. M., \& Bean, B. (2011). Can social marketing segmentation initiatives be used to increase household electricity conservation? Journal of Non-profit and Public Sector Marketing, 23(3), 269-305.

Grönroos, C. (1997). Value-driven relational marketing: From products to resources and competencies. Journal of Marketing Management, 13(5), 407-419.

Grönroos, C., \& Voima, P. (2013). Critical service logic: Making sense of value creation and co-creation. Journal of the Academy of Marketing Science, 41(2), 133-150.

Gubbi, J., Buyya, R., Marusic, S., \& Palaniswami, M. (2013). Internet of things (IoT): A vision, architectural elements, and future directions. Future Generation Computer Systems, 29(7), 1645-1660.

Gummerus, J. (2013). Value creation processes and value outcomes in marketing theory: Strangers or siblings? Marketing Theory, 13(1), $19-46$.

Gutman, J. (1982). A means-end chain model based on consumer categorization processes. The Journal of Marketing, 46(2), 60-72.

Ha, S., \& Stoel, L. (2009). Consumer e-shopping acceptance: Antecedents in a technology acceptance model. Journal of Business Research, 62(5), 565-571.

Halkier, B., Katz-Gerro, T., \& Martens, L. (2011). Applying practice theory to the study of consumption: Theoretical and methodological considerations. Journal of Consumer Culture, 11(1), 3-13.

Hand, M., \& Shove, E. (2007). Condensing practices: Ways of living with a freezer. Journal of Consumer Culture, 7(1), 79-104.

Heinonen, K., Strandvik, T., Mickelsson, K. J., Edvardsson, B., Sundström, E., \& Andersson, P. (2010). A customer-dominant logic of service. Journal of Service Management, 21(4), 531-548.

Helkkula, A., Kelleher, C., \& Pihlström, M. (2012). Characterizing value as an experience: Implications for service researchers and managers. Journal of Service Research, 15(1), 59-75.

Hérault, S., \& Belvaux, B. (2014). Privacy paradox and the adoption of intrusive technologies. The case of mobile location-based services. Décisions Marketing, 74, 67-82.

Heskett, J. L., Sasser, W. E., \& Schlesinger, L. A. (1997). The service profit chain. New York: The Free Press. 
Hilton, T., \& Hughes, T. (2013). Co-production and self-service: The application of service-dominant logic. Journal of Marketing Management, 29(7-8), 861-881.

Holttinen, H. (2010). Social practices as units of value creation: Theoretical underpinnings and implications. International Journal of Quality and Service Sciences, 2(1), 95-112.

Holttinen, H. (2014). Contextualizing value propositions: Examining how consumers experience value propositions in their practices. Australasian Marketing Journal, 22(2), 103-110.

Huber, J., Lynch, J., Corfman, K., Feldman, J., Holbrook, M., Lehmann, D., Munier, B., Schkade, D., \& Simonson, I. (1997). Thinking about values in prospect and retrospect: Maximizing experienced utility. Marketing Letters, 8(3), 323-334.

Hutchby, I. (2001). Technologies, texts and affordances. Sociology, 35(2), $441-456$

Ilmonen, K. (2004). The use of and commitment to goods. Journal of Consumer Culture, 4(1), 27-50.

Jaakkola, E., \& Alexander, M. (2014). The role of customer engagement behavior in value co-creation a service system perspective. Journal of Service Research, 17(3), 247-261.

Kazmina, M. G., Manykin, E., \& Grichuck, E. (2014). Oscillatory neural networks: In problems of parallel information processing. Berlin/ Boston: De Gruyter.

Kleinaltenkamp, M., Brodie, R. J., Frow, P., Hughes, T., Peters, L. D., \& Woratschek, H. (2012). Resource integration. Marketing Theory, 12(2), 201-205.

Latour, B. (1987). Science in action: How to follow scientists and engineers through society. Boston: Harvard University Press.

Latour, B. (1993). We have never been modern. Brighton: Harvester Wheatsheaf.

Latour, B. (2005). Re-assembling the social: An introduction to actor network theory. New York: Oxford University Press.

Laud, G., Karpen, I. O., Mulye, R., \& Rahman, K. (2015). The role of embeddedness for resource integration: Complementing SD logic research through a social capital perspective. Marketing Theory, 15(4), 509-543.

Laukkanen, T. (2016). Consumer adoption versus rejection decisions in seemingly similar service innovations: The case of the internet and mobile banking. Journal of Business Research, 69(7), 2432-2439.

Law, J. (1992). Notes on the theory of the actor-network: Ordering, strategy, and heterogeneity. Systems Practice, 5(4), 379-393.

Lazar, A., Koehler, C., Tanenbaum, J. \& Nguyen, D.H. (2015). Why we use and abandon smart devices. In Proceedings of the 2015 ACM International Joint Conference on Pervasive and Ubiquitous Computing (pp. 635-646). Osaka, Japan. 07-11 September.

Leonardi, P. M. (2011). When flexible routines meet flexible technologies: Affordance, constraint, and the imbrication of human and material agencies. MIS Quarterly, 35(1), 147-167.

Leonardi, P. M. (2013). Theoretical foundations for the study of sociomateriality. Information and Organization, 23(2), 59-76.

Lin, J. S. C., \& Hsieh, P. L. (2011). Assessing the self-service technology encounters: Development and validation of SSTQUAL scale. Journal of Retailing, 87(2), 194-206.

Little, D. (2012). The social world as morphogenesis. Understanding Society, May 23. http://understandingsociety.blogspot.co.uk/2012/ 05/social-world-as-morphogenesis.html. Accessed 20 Aug 2016.

Löbler, H. (2011). Position and potential of service-dominant logic-evaluated in an 'ism' frame for further development. Marketing Theory, 11(1), 51-73.

Löbler, H., \& Lusch, R. F. (2014). Signs and practices as resources in ITrelated service innovation. Service Science, 6(3), 1-16.

Lusch, R. F., \& Vargo, S. L. (2014). Service-dominant logic: Premises, perspectives, possibilities. Cambridge: Cambridge University Press.

Malafouris, L. (2013). How things shape the mind. Cambridge: The MIT Press.
Mani, Z., \& Chouk, I. (2016). Drivers of consumers' resistance to smart products. Journal of Marketing Management, 33(1/2), 1-22.

Markus, M. L., \& Silver, M. S. (2008). A foundation for the study of IT effects: A new look at DeSanctis and Poole's concepts of structural features and spirit. Journal of the Association for Information Systems, 9(10/11), 609-632.

Mayr, T., \& Zins, A. H. (2012). Extensions on the conceptualization of customer perceived value: Insights from the airline industry. International Journal of Culture, Tourism and Hospitality Research, 6(4), 356-376.

Meuter, M. L., Ostrom, A. L., Roundtree, R. I., \& Bitner, M. J. (2000). Self-service technologies: Understanding customer satisfaction with technology-based service encounters. Journal of Marketing, 64(3), $50-64$.

Meuter, M. L., Ostrom, A. L., Bitner, M. J., \& Roundtree, R. (2003). The influence of technology anxiety on consumer use and experiences with self-service technologies. Journal of Business Research, 56(11), 899-906.

Mick, D. G. (2006). Meaning and mattering through transformative consumer research. Advances in Consumer Research, 33(2), 1-4.

Mick, D. G., \& Fournier, S. (1998). Paradoxes of technology: Consumer cognizance, emotions, and coping strategies. Journal of Consumer Research, 25(2), 123-143.

Moody, J., \& White, D. R. (2003). Structural cohesion and embeddedness: A hierarchical concept of social groups. American Sociological Review, 68(1), 103-127.

Moreno-Munoz, A., Bellido-Outeirino, F. J., Siano, P., \& Gomez-Nieto, M. A. (2016). Mobile social media for smart grids customer engagement: Emerging trends and challenges. Renewable and Sustainable Energy Reviews, 53, 1611-1616.

Ng, I. C., \& Smith, L. A. (2012). An integrative framework of value. Review of Marketing Research, 9, 207-243.

Norman, D. A. (1988). The psychology of everyday things. New York: Basic Books.

Oh, H. (1999). Service quality, customer satisfaction, and customer value: A holistic perspective. International Journal of Hospitality Management, 18(1), 67-82.

Orlikowski, W. J. (2007). Sociomaterial practices: Exploring technology at work. Organization Studies, 28(9), 1435-1448.

Orlikowski, W. J. (2009). The sociomateriality of organizational life: Considering technology in management research. Cambridge Journal of Economics, 34, 125-141.

Ostrom, A., \& Iacobucci, D. (1995). Consumer trade-offs and the evaluation of services. Journal of Marketing, 59(1), 17-28.

Ostrom, A. L., Parasuraman, A., Bowen, D. E., Patricio, L., Voss, C. A., \& Lemon, K. (2015). Service research priorities in a rapidly changing context. Journal of Service Research, 18(2), 127-159.

Owens, S., \& Driffill, L. (2008). How to change attitudes and behaviors in the context of energy. Energy Policy, 36(12), 4412-4418.

Packard, V. (1957). The hidden persuaders. London: Longmans, Green.

Parasuraman, A. (2000). Technology readiness index (TRI) a multipleitem scale to measure readiness to embrace new technologies. Journal of Service Research, 2(4), 307-320.

Patsiotis, A. G., Hughes, T., \& Webber, D. J. (2013). An examination of consumers' resistance to computer-based technologies. Journal of Services Marketing, 27(4), 294-311.

Portet, F., Vacher, M., Golanski, C., Roux, C., \& Meillon, B. (2013). Design and evaluation of a smart home voice interface for the elderly: Acceptability and objection aspects. Personal and Ubiquitous Computing, 17(1), 127-144.

Ramaswamy, V. (2008). Co-creating value through customers' experiences: The Nike case. Strategy \& Leadership, 36(5), 9-14.

Reckwitz, A. (2002). Toward a theory of social practices: A development in culturalist theorizing. European Journal of Social Theory, 5(2), $243-263$ 
Reinders, M. J., Frambach, R., \& Kleijnen, M. (2015). Mandatory use of technology-based self-service: Does expertise help or hurt? European Journal of Marketing, 49(1/2), 190-211.

Rodríguez, J. P., Beard, T. D., Bennett, E. M., Cumming, G. S., Cork, S. J., Agard, J., Dobson, A. P., \& Peterson, G.D. (2006). Trade-offs across space, time, and ecosystem services. Ecology and Society, 11(1), art. 28. http://www.ecologyandsociety.org/vol11/iss1/art28/. Accessed 26 Sept 2015.

Rogers, E. (2003). The diffusion of innovations (fifth ed.). New York: The Free Press.

Rouse, J. (2001). Practice as collective action. In T. R. Schatzki, K. K. Cetina \& E. Von Savigny, The practice turn in contemporary society. New York: Routledge (198-208).

Ruiz, D. M., Gremler, D. D., Washburn, J. H., \& Carrión, G. C. (2008). Service value revisited: Specifying a higher-order, formative measure. Journal of Business Research, 61(12), 1278-1291.

Sashi, C. M. (2012). Customer engagement, buyer-seller relationships, and social media. Management Decision, 50(2), 253-272.

Schatzki, T. (1996). Social practices. Cambridge: Cambridge University Press.

Schau, H. J., Muñiz Jr., A. M., \& Arnould, E. J. (2009). How brand community practices create value. Journal of Marketing, 73(5), $30-51$.

Shove, E. (2003). Converging conventions of comfort, cleanliness and convenience. Journal of Consumer Policy, 26(4), 395-418.

Shove, E., \& Pantzar, M. (2005). Consumers, producers and practices: Understanding the invention and reinvention of Nordic walking. Journal of Consumer Culture, 5(1), 43-64.

Shove, E., Watson, M., Hand, M., \& Ingram, J. (2007). The design of everyday life. Oxford: Berg.

Skålén, P., \& Edvardsson, B. (2016). Transforming from the goods to the service-dominant logic. Marketing Theory, 16(1), 101-121.

Skålén, P., Gummerus, J., von Koskull, C., \& Magnusson, P. R. (2015a). Exploring value propositions and service innovation: A servicedominant logic study. Journal of the Academy of Marketing Science, 43(2), 137-158.

Skålén, P., Pace, S., \& Cova, B. (2015b). Firm-brand community value co-creation as alignment of practices. European Journal of Marketing, 49(3/4), 596-620.

Smith, B. (1988). Gestalt theory: An essay in philosophy. In Foundations of Gestalt theory, B. Smith (ed.), Munich and Vienna: Philosophia Verlag (11-81).

So, K., King, C., \& Sparks, B. (2014). Customer engagement with tourism brands: Scale development and validation. Journal of Hospitality and Tourism Research, 38(3), 304-329.

Storbacka, K., Brodie, R. J., Böhmann, T., Maglio, P. P., \& Nenonen, S. (2016). Actor engagement as a microfoundation for value co-creation. Journal of Business Research, 69(8), 3008-3017.

Timm, T. (2016). The government just admitted it will use smart home devices for spying. The Guardian, February 9, 2016. https://www. theguardian.com/commentisfree/2016/feb/09/internet-of-thingssmart-devices-spying-surveillance-us-government. Accessed 14 July 2016.

Torriti, J., Leach, M., \& Devine-Wright, P. (2011). Demand side participation: Price constraints, technical limits and behavioral risks. The future of electricity demand: Customers, citizens and loads. Department of Applied Economics Occasional Papers. Cambridge: Cambridge University Press (88-105).

Tseng, K. C., Hsu, C. L., \& Chuang, Y. H. (2013). Designing an intelligent health monitoring system and exploring user acceptance for the elderly. Journal of Medical Systems, 37(6), 9967.
Tynan, C., McKechnie, S., \& Hartley, S. (2014). Interpreting value in the customer service experience using customer-dominant logic. Journal of Marketing Management, 30(9-10), 1058-1081.

Vargo, S. L., \& Lusch, R. F. (2004). Evolving to a new dominant logic for marketing. Journal of Marketing, 68(1), 1-17.

Vargo, S. L., \& Lusch, R. F. (2008). Service-dominant logic: Continuing the evolution. Journal of the Academy of Marketing Science, 36(1), 1-10.

Vargo, S. L., \& Lusch, R. F. (2016). Institutions and axioms: An extension and update of service-dominant logic. Journal of the Academy of Marketing Science, 44(1), 5-23.

Vivek, S. D., Beatty, S. E., \& Morgan, R. M. (2012). Customer engagement: Exploring customer relationships beyond purchase. Journal of Marketing Theory and Practice, 20(2), 122-146.

Walker, K. L. (2016). Surrendering information through the looking glass: Transparency, trust, and protection. Journal of Public Policy \& Marketing, 35(1), 144-158.

Wang, C., Harris, J., \& Patterson, P. (2013). The roles of habit, selfefficacy, and satisfaction in driving continued use of self-service technologies: A longitudinal study. Journal of Service Research, 16(3), 400-414.

Warde, A. (2005). Consumption and theories of practice. Journal of Consumer Culture, 5(2), 131-153.

Warde, A. (2014). After taste: Culture, consumption and theories of practice. Journal of Consumer Culture, 14(3), 279-303.

Watson, M., \& Shove, E. (2008). Product, competence, project and practice: DIY and the dynamics of craft consumption. Journal of Consumer Culture, 8(1), 69-89.

Westaby, J. D. (2005). Behavioral reasoning theory: Identifying new linkages underlying intentions and behavior. Organizational Behavior and Human Decision Processes, 98(2), 97-120.

Wieland, H., Polese, F., Vargo, S., \& Lusch, R. (2012). Toward a service (eco) systems perspective on value creation. International Journal of Service Science, Management, Engineering and Technology, 3(3), $12-24$.

Weiser, M., \& Brown, J. S. (1997). The coming age of calm technology. In P. J. Denning \& R. M. Metcalfe (Eds.), Beyond calculation (pp. 75-85). New York: Springer.

Wilson, C., Hargreaves, T., \& Hauxwell-Baldwin, R. (2015). Smart homes and their users: A systematic analysis and key challenges. Personal and Ubiquitous Computing, 19(2), 463-476.

Witztum, E., Van der Hart, O., \& Friedman, B. (1988). The use of metaphors in psychotherapy. Journal of Contemporary Psychotherapy, 18(4), 270-290.

Woodall, T. (2003). Conceptualizing "value for the customer": An attributional, structural and dispositional analysis. Academy of Marketing Science Review, 12(1), 1-42.

Woodall, T., Hiller, A., \& Resnick, S. (2014). Making sense of higher education: Students as consumers and the value of the university experience. Studies in Higher Education, 39(1), 48-67.

Wuenderlich, N. V., Heinonen, K., Ostrom, A. L., Patricio, L., Sousa, R., Voss, C., \& Lemmink, J. G. (2015). "Futurizing" smart service: Implications for service researchers and managers. Journal of Services Marketing, 29(6/7), 442-447.

Yadav, M. S., \& Pavlou, P. A. (2014). Marketing in computer-mediated environments: Research synthesis and new directions. Journal of Marketing, 78(1), 20-40.

Yang, H., Lee, H., \& Zo, H. (2017). User acceptance of smart home services: An extension of the theory of planned behavior. Industrial Management \& Data Systems, 117(1), 68-89. 